\title{
The Future of Local Research Review
}

\author{
William 0. Myers, MD, Marshfield Medical Research Foundation, Marshfield, Wisconsin
}

[See related article: 63 - 68]

\section{REPRINT REQUESTS:}

William 0. Myers, MD

Marshfield Medical Research Foundation

1000 North Oak Avenue

Marshfield, WI 54449

Email: myers.william@marshfieldclinic.org

KEYWORDS:

Ethics Committees; Research
Institutional review boards (IRBs) were mandated by the Public Health Service Act of 1974 for institutions receiving federal research money. Recent highly publicized research disasters have called into question the effectiveness and future of the IRB system in the United States. A review by the Office of the Inspector General in 1998 was critical of IRBs as presently constituted.

In April 2002, I had the opportunity to attend a lecture of Daniel Icenogle, MD, JD, given on the future of IRBs, especially the question of legal exposure. The paper presented in this issue of Clinical Medicine \& Research is entitled, not entirely reassuringly, IRBs, Conflict and Liability: Will We See IRBs in Court? Or is it when?

The report by Dr. Icenogle is well worth reading, and reading again. He demonstrates how the IRB is potentially caught between industry pressure to get studies underway and ultimately done (favorably, one infers) and public pressures (which include the legal system) to do them correctly with all the safeguards for subjects, participants and patients, possible. People want no risk from research but most know there is going to be some risk, some unknown, but want the risk as small as possible and want what is known to be communicated clearly with all questions answered that are capable of answers.

Dr. Icenogle reviews recent research fatalities and their causes. He discusses the court cases that resulted and provides insight into the state and federal court process. Dr. Icenogle identifies the ignoring of regulations by investigators, failure to disclose risks, failure to deal with financial conflicts of interest and the lack of fully informed consent, as causes for the court cases.

We should not be trapped by "It can't happen here" thinking, and we need to be vigilant and alert for research ethics violations. Those of us who serve on IRBs, Animal Care, Research and Conflict of Interest committees, in addition to hospital, clinic and foundation administrators, all need to pay attention and commit to the endeavor to maintain a highly ethical research effort every day. Let's keep our research subjects safe and pleased to participate, and maybe we'll stay out of court. 